\title{
openheart Influence of health-related quality of life on time from symptom onset to hospital arrival and the risk of readmission in patients with myocardial infarction
}

\author{
Catrin Henriksson, ${ }^{1}$ Margareta Larsson, ${ }^{2}$ Johan Herlitz, ${ }^{3}$ Jan-Erik Karlsson, ${ }^{4}$ \\ Lisa Wernroth, ${ }^{5}$ Bertil Lindahl ${ }^{1}$
}

To cite: Henriksson C, Larsson M, Herlitz J, et al. Influence of health-related quality of life on time from symptom onset to hospital arrival and the risk of readmission in patients with myocardial infarction. Open Heart 2014;1:e000051. doi:10.1136/openhrt-2014000051

Received 24 February 2014 Revised 24 July 2014 Accepted 21 November 2014

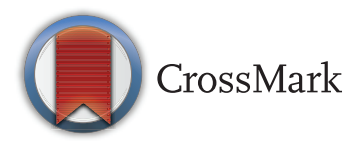

${ }^{1}$ Department of Medical Sciences, Uppsala Clinical Research Center, Uppsala University, Uppsala, Sweden 2Department of Women's and Children's Health, Uppsala University, Uppsala, Sweden ${ }^{3}$ The Center of Prehospital Research in Western Sweden, University of Borås and Sahlgrenska University Hospital, Gothenburg, Sweden

${ }^{4}$ Department of Cardiology, Ryhov Hospital, Jönköping, Sweden

${ }^{5}$ Uppsala Clinical Research Center, Uppsala University, Uppsala, Sweden

Correspondence to Dr Catrin Henriksson; catrin. henriksson@ucr.uu.se

\section{ABSTRACT}

Background: Despite increased awareness of the importance of early treatment in acute myocardial infarction (AMI), the delay from symptom onset to hospital arrival is still too long and rehospitalisations are frequent. Little is known about how health-related quality of life (HRQL) affects delay time and the frequency of readmissions.

Method: We used quality registers to investigate whether patients' HRQL has any impact on delay time with a new AMI, and on the rate of readmissions during the first year. Patients with $\mathrm{AMI}<75$ years, with HRQL assessed with EQ-5D at 1-year follow-up, and who thereafter had a new AMI registered, were evaluated for the correlation between HRQL and delay time $(n=454)$. The association between HRQL and readmissions was evaluated among those who had an additional AMI and a new 1-year follow-up registration $(\mathrm{n}=216)$.

Results: Patients who reported poor total health status (EQ-VAS $\leq 50$ ), compared to those who reported EQ-VAS 81-100, had tripled risk to delay $\geq 2 \mathrm{~h}$ from symptom onset to hospital arrival (adjusted OR 3.01, $95 \% \mathrm{Cl} 1.43$ to 6.34 ). Patients scoring EQ-VAS $\leq 50$ had also a higher risk of readmissions in the univariate analysis (OR $3.08,95 \% \mathrm{Cl} 1.71$ to 5.53 ). However, the correlation did not remain significant after adjustment (OR 1.99, 95\% Cl 0.90 to 4.38). EQ-index was not independently associated with delay time or readmissions.

Conclusions: Aspects of total health status post-AMI were independently associated with delay time to hospital arrival in case of a new AMI. However, the influence of total health status on the risk of readmissions was less clear.

\section{INTRODUCTION}

The first few hours after symptom onset are the most critical in acute myocardial infarction (AMI). In ST-elevation myocardial infarctions (STEMI) the majority of deaths occur

\section{KEY QUESTIONS}

What is already known about this subject?

- Prior studies have shown that patients with acute myocardial infarction (AMI) often delay in seeking medical care, and there are several factors influencing the decision process. Reinfarctions and readmissions to hospital decreases health-related quality of life (HRQL), and patients with AMI are known to have worse $H R Q L$ than the general population.

What does this study add?

- Patients who experienced poor total health status (EQ-VAS) had a delay time exceeding two hours more often in comparison to those who reported high scores of EQ-VAS.

- Poor total health status also indicated higher risks of readmissions in the univariate analysis.

How might this impact on clinical practice?

- Information and education about the importance of seeking medical care in case of suspected myocardial infarction symptoms should be imparted. Patients should be aware of a possible cardiac event so as to inform their relatives. Information and education should also be provided in primary care clinics and to the general population. As per modern practise, healthcare personnel should measure patients' HRQL routinely and observe those reporting low scores. Patients experiencing poor HRQL should be given special attention and support, preferably by a psychologist or specially educated nurse.

during the first hours after symptom onset, ${ }^{1-4}$ and the beneficial effects of reperfusion treatment are critically time dependent. ${ }^{1} \quad 3-5$ However, patients suffering from AMI commonly delay seeking medical care. ${ }^{6} 7$ Several factors are known to influence the patient's decision time before going to hospital: age, 
gender, level of knowledge/awareness, appraisal of symptoms, psychosocial factors, depression and the attitude of people in proximity to the patient. ${ }^{8-10}$

Secondary prevention treatment after AMI has improved considerably over recent decades, and decreases the risk for new cardiac events. ${ }^{11-13}$ However, readmissions to hospital after an AMI are still common during the first 6-12 months. ${ }^{14}$ Known factors contributing to readmission are older age, heart failure, diabetes and depression. ${ }^{15} 16$

Delay time from onset of symptoms to admission to hospital, readmissions and health-related quality of life (HRQL) measured by EQ-5D, are all registered in the Swedish national quality registers of patients with AMI; RIKS-HIA (The Register of Information and Knowledge about Swedish Heart Intensive Care Administrations) ${ }^{17}$ and SEPHIA (Secondary Prevention after Heart Intensive Care Admission).${ }^{18}$

Patients with AMI commonly indicate lower HRQL scores than the general public do. ${ }^{19}$

It is not clear to what extent psychological support aimed to increase HRQL affects delay time and frequency of readmissions. There is also lack of data on whether HRQL has any impact on delay time and the rate of readmissions after AMI. Therefore, the aim of this study was to assess the influence of HRQL post-AMI on the delay time from symptom onset to hospital admission and on the risk of readmission.

\section{METHODS}

\section{RIKS-HIA}

More than $95 \%$ of all patients with AMI admitted to cardiology departments in Sweden are registered in RIKS-HIA. ${ }^{17}$ Information about patients with suspected acute coronary syndrome is entered, with no age limit for enrolment into the register. Information about the patients' background characteristics, time of symptom onset and time of arrival to hospital are registered, as well as prehospital treatment, investigations and treatments during hospital stay.

\section{SEPHIA}

Patients below 75 years of age with index AMI registered in RIKS-HIA are followed up with two out-clinic visits or telephone contacts. The first follow-up occurs $6-10$ weeks after discharge, and the second follow-up after 12-14 months. Recorded variables in SEPHIA are HRQL measured by EuroQol-5 dimension (EQ-5D), cardiac-related symptoms, occupation, readmissions, investigations and treatments after discharge, and risk factors for cardiovascular disease. Measurements of blood pressure, lipids, glycated haemoglobin (HbAlc) in patients with diabetes, participation in secondary prevention programmes and compliance to medication are also recorded.

\section{Study population}

The study was comprised of 45868 patients diagnosed with AMI (International Classification of Diseases (ICD) 10-code I21, I22), <75 years old, admitted to hospital and registered in RIKS-HIA during 2005-2009. Of these patients, 18015 were enrolled in SEPHIA and had at least 1-year follow-up registration, including HRQL measurement. Two subsets of the total SEPHIA population were included in the study, one for the evaluation of the relationship between HRQL and delay time ('Delay Time Population'); and one for the evaluation of the association between HRQL and readmissions ('Re-Admission Population'; figure 1). The Delay Time Population consisted of patients who had an additional AMI registered in RIKS-HIA after the initial event $(\mathrm{n}=454)$. The Re-Admission Population had also completed the 1-year follow-up registration in SEPHIA after the new AMI $(n=216)$.

\section{HRQL measurements}

EuroQol-5 dimension (EQ-5D) is a generic measure of health status developed by the EuroQoL group. ${ }^{20}$ Patients estimate their health status in five dimensions: mobility, self-care, usual activities, pain/discomfort and anxiety/depression. Each dimension is rated on the following levels: (1) no problems, (2) some problems and (3) extreme problems. A summary of these dimensions forms an EQ-index with the maximum score equal to 1.0. The patients also estimate their total health status on a self-rating $20 \mathrm{~cm}$, vertical scale with the end points 'Best imaginable health state' (100) and 'Worst imaginable health state' $(0) .{ }^{20}$ EQ-5D has previously been validated for patients with acute coronary syndrome. ${ }^{21} 22$

In the current study the EQ-5D was measured in median 325 days (25th-75th percentile; 125-604) before the new AMI, and was considered to represent the patient's HRQL at the time of the new AMI. In the analysis we divided the patients into four groups based on quartiles of the EQ-VAS $(0-50,51-70,71-80$ and 81-100) and EQ-index $(\leq 0.66,0.67$ to $0.73,0.74-0.99$ and 1.0).

\section{Definitions}

- Time of symptom onset: The time of onset of patient's symptoms before taking the decision to seek acute medical care.

- Patients' delay time: The time from symptom onset to hospital arrival.

- Hospital admission time: The patients' arrival time at the emergency department, cardiology department directly or the percutaneous coronary intervention unit directly, whichever was first.

- Readmissions: all readmissions to hospital regardless of diagnosis.

\section{Statistics}

Continuous variables are reported as medians with 25th and 75th percentiles (Q1, Q3) and categorical variables are reported as frequencies and percentages.

The two end points analysed were delay time, classified into short $(<2 \mathrm{~h})$ and long $(\geq 2 \mathrm{~h})$ delay time and 


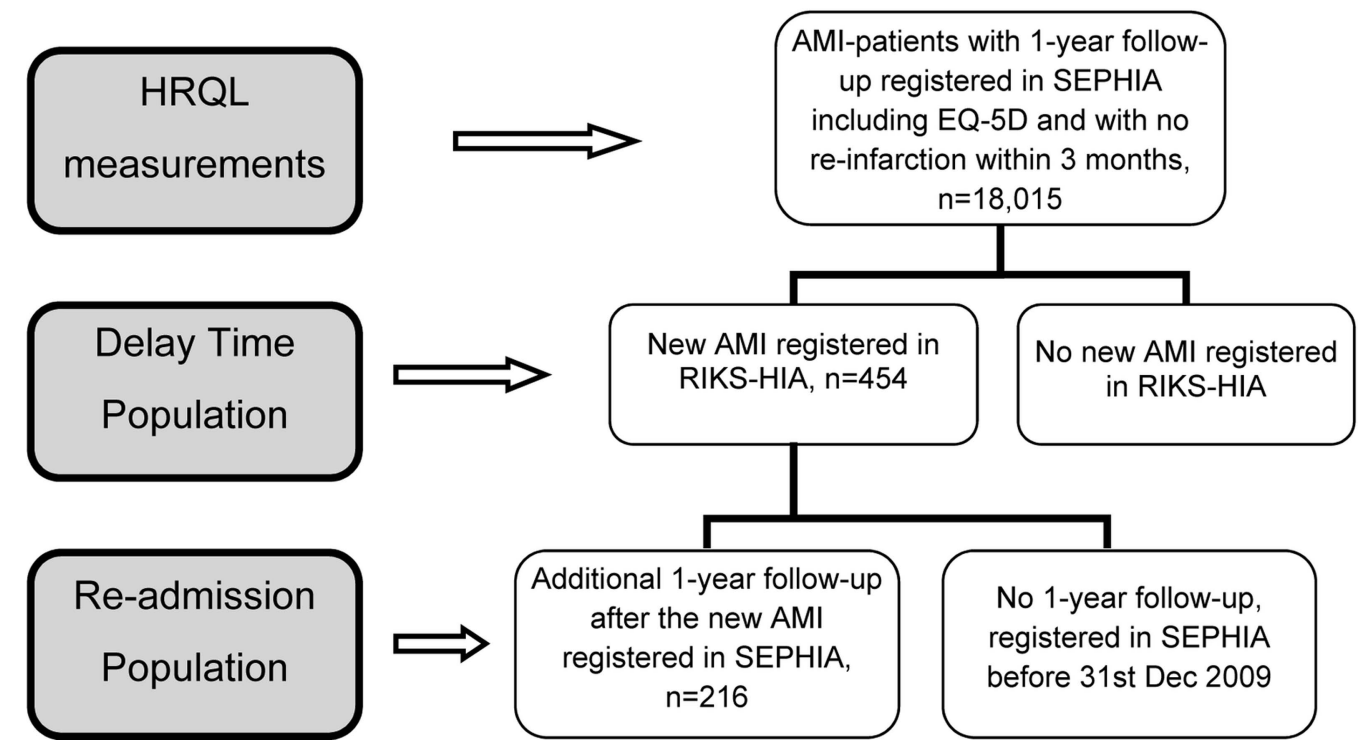

Figure 1 Flow chart of the populations (AMI, acute myocardial infarction; HRQL, health-related quality of life).

readmission. We selected a cut-off point of $2 \mathrm{~h}$ for delay time in light of previously reported data ${ }^{6}$ and the distribution of delay time in this study.

The associations between the two end points and EQ-index, EQ-VAS, chest pain, dyspnoea and anxiety/ depression, respectively, were assessed with a logistic generalised estimating equations (GEE) logistic regression model. ${ }^{23}$ An exchangeable correlation structure was used to check for the dependence between patients from the same hospital. Results from the GEE logistic regression models were presented as estimated OR with 95\% CIs, and a $\mathrm{p}$ value for test of the null hypothesis that the true OR is unity.

The median time between 1-year follow-up in SEPHIA and date of a new AMI registered in RIKS-HIA was 325 days $(\mathrm{Q} 1=125, \mathrm{Q} 3=604)$ and was classified into short ( $<325$ days) and long ( $\geq 325$ days) time.

Subgroup analyses were performed for gender and time between the HRQL measurement in SEPHIA and a new AMI registered in RIKS-HIA.

Spearman's rank-order correlation ( $r$ ) was used to describe the relationship between EQ-VAS and EQ-index. Models with delay time as outcome were adjusted for clinically relevant risk factors including age, ambulance, diabetes, gender, history of heart failure, hypertension, prehospital ECG, previous percutaneous coronary intervention (PCI), previous stroke, previous coronary artery bypass grafting, pulmonary rales, reperfusion treatment, STEMI and year. The models with readmission as outcome were adjusted for the same variables as delay time but also for the number of medications at discharge after the new event and PCI during hospital stay but not for pulmonary rales and reperfusion treatment. All the mentioned covariates were used in the results.

All statistical tests and CIs are two-sided and $\mathrm{p}<0.05$ was considered statistically significant. All calculations were performed with SAS V.9.2 (SAS Institute Inc, Cary, North Carolina, USA).

\section{Hypothesis}

We supposed that long delay time is associated with poorer quality of life and with higher risk of readmissions.

\section{Ethics}

According to Swedish law no written informed consent is needed to register a patient in RIKS-HIA and SEPHIA. However, all patients must be informed of their participation in the register and have the right to withdraw their participation.

The study was approved by the Regional Medical Ethical Committee in Uppsala.

\section{RESULTS}

\section{Background characteristics}

The median age was comparable between the study populations and the total SEPHIA population, but the study populations had more comorbidities (table 1). The delay time was shorter in the study populations than in the total SEPHIA population.

\section{Depression/anxiety}

The majority (59\%) of the study population had no problems with depression/anxiety 1 year post-MI, 37\% reported moderate depression/anxiety and only $4 \%$ reported extreme problems. In the total SEPHIA population $64 \%$ had no problems with depression/anxiety, $32 \%$ reported moderate problems and $3 \%$ had extreme problems. 
Table 1 Background characteristics

\begin{tabular}{|c|c|c|c|}
\hline Variable & $\begin{array}{l}\text { Delay time } \\
\text { population } \\
\mathrm{N}=454\end{array}$ & $\begin{array}{l}\text { Readmission } \\
\text { population } \\
\mathrm{N}=216\end{array}$ & $\begin{array}{l}\text { Total } \\
\text { SEPHIA-population } \\
\mathrm{N}=18015\end{array}$ \\
\hline Age (years) median & 65.0 & 64.0 & 65.0 \\
\hline$(Q 1-Q 3)$ & $(59.0-70.0)$ & $(59.0-70.0)$ & $(59.0-70.0)$ \\
\hline Women & $98(21.6)$ & $42(19.4)$ & $4761(26.4)$ \\
\hline Ambulance to cardiology department/PCI unit & $79(17.4)$ & $38(17.6)$ & $4282(23.8)$ \\
\hline Ambulance to the emergency department & $214(47.1)$ & $103(47.7)$ & $5838(32.4)$ \\
\hline Prehospital ECG & $200(44.1)$ & $96(44.4)$ & $6302(35.0)$ \\
\hline Delay time & 153.0 & 144.0 & 188.0 \\
\hline Median, $\min (\mathrm{Q} 1-\mathrm{Q} 3)$ & $(90.0-420.0)$ & $(90.0-400.0)$ & $(91.5-555.0)$ \\
\hline Missing & $29(6.4)$ & $7(3.2)$ & $1163(6.5)$ \\
\hline Diabetes mellitus & $172(37.9)$ & $68(31.5)$ & 3459 (19.2) \\
\hline History of heart failure & $70(15.4)$ & $28(13.0)$ & $500(2.8)$ \\
\hline Hypertension & $238(52.4)$ & $114(52.8)$ & 7267 (40.3) \\
\hline Prior $\mathrm{PCl}$ & $354(78.0)$ & 177 (81.9) & $1784(9.9)$ \\
\hline Prior CABG & 101 (22.2) & $40(18.5)$ & $1085(6.0)$ \\
\hline \multicolumn{4}{|l|}{ Type of AMI } \\
\hline NSTEMI & 355 (78.2) & $165(76.4)$ & 11338 (62.9) \\
\hline STEMI & $96(21.1)$ & $50(23.1)$ & $6617(36.7)$ \\
\hline \multicolumn{4}{|l|}{ Reperfusion treatment } \\
\hline Acute CABG & 0 & 0 & $31(0.2)$ \\
\hline $\begin{array}{l}\text { Acute coronary angiography without } \\
\text { intervention }\end{array}$ & $16(3.5)$ & $9(4.2)$ & $438(2.4)$ \\
\hline Primary $\mathrm{PCl}$ & $91(20.0)$ & $45(20.8)$ & $5958(33.1)$ \\
\hline Thrombolysis & $6(1.3)$ & $3(1.4)$ & $821(4.6)$ \\
\hline \multicolumn{4}{|l|}{ Pulmonary rales } \\
\hline Basal rales & $40(8.8)$ & $17(7.9)$ & $729(4.0)$ \\
\hline Rales more than half lungs & $4(0.9)$ & $2(0.9)$ & $87(0.5)$ \\
\hline Pulmonary oedema & $5(1.1)$ & $2(0.9)$ & $128(0.7)$ \\
\hline Missing & $39(8.6)$ & $23(10.6)$ & $1367(7.6)$ \\
\hline \multicolumn{4}{|l|}{ Left ventricular function } \\
\hline Normal (EF $\geq 50 \%)$ & $172(37.9)$ & $80(37.0)$ & $8666(48.1)$ \\
\hline Slightly decreased (EF 40-49\%) & $63(13.9)$ & $31(14.4)$ & $3252(18.1)$ \\
\hline Moderately decreased (EF 30-39\%) & $41(9.0)$ & $26(12.0)$ & $1889(10.5)$ \\
\hline Severely decreased (EF <30\%) & $20(4.4)$ & $7(3.2)$ & $559(3.1)$ \\
\hline Missing & $156(34.4)$ & $71(32.9)$ & 3478 (19.3) \\
\hline \multicolumn{4}{|l|}{ Number of medications at discharge* } \\
\hline 0 & $6(1.3)$ & 0 & $16(0.1)$ \\
\hline$\leq 3$ & $32(7)$ & $9(4.1)$ & $1750(9.7)$ \\
\hline $4-5$ & $318(70)$ & $157(72.7)$ & $15155(84.1)$ \\
\hline$\geq 6$ & $90(19.8)$ & $49(22.7)$ & $974(5.4)$ \\
\hline
\end{tabular}

Median (Q1-Q3) or $\mathrm{n}(\%)$.

*Type of medications: aspirin, other antiplatelet agents, $\beta$-blockers, ACE inhibitors/A2 blockers, statins, other lipid lowering agents, nitrates. $\mathrm{AMI}$, acute myocardial infarction; CABG, coronary artery bypass grafting; EF, ejection fraction; NSTEMI, non-ST-elevation myocardial infarction; PCl, percutaneous coronary intervention; STEMI, ST-elevation myocardial infarction.

\section{Cardiac symptoms}

The median EQ-index was higher for the total SEPHIA population, and more patients in this group reported high EQ-VAS scores (81-100) compared to the study populations. Patients in the study had more symptoms of angina and dyspnoea than patients in the total SEPHIA population. The EQ-5D scores are shown in table 2.

\section{EQ-index and EQ-VAS correlations}

There was a moderate correlation between EQ-VAS and EQ-index, Spearman's $r=0.57(\mathrm{p}<0.001)$, both in the delay time population and the total SEPHIA population. The correlations between EQ-VAS and the different subcomponents of EQ-index were also modest $(-0.27$ to -0.47$)$.

\section{Delay time}

Fifty-seven per cent of the study population had a delay time, from symptom onset to hospital arrival, of $2 \mathrm{~h}$ or more, and the delay time increased with each quartile of EQ-VAS and EQ-index, respectively (tables 3 and 4).

Patients who scored EQ-VAS $\leq 50$, compared to those who scored EQ-VAS 81-100, had an unadjusted OR for a delay $\geq 2 \mathrm{~h}$ before hospital admission of 2.86 (95\% CI 1.47 to 5.54 ), and an adjusted OR of 3.01 (95\% CI 1.43 
Table 2 EQ-5D in relation to delay time and readmission

\begin{tabular}{|c|c|c|c|}
\hline Variable & $\begin{array}{l}\text { Delay time population } \\
\mathrm{N}=454\end{array}$ & $\begin{array}{l}\text { Readmission population } \\
\mathrm{N}=216\end{array}$ & $\begin{array}{l}\text { Total SEPHIA population } \\
\mathrm{N}=18015\end{array}$ \\
\hline \multicolumn{4}{|l|}{ EQ-index, n (\%) } \\
\hline Median (Q1, Q3) & $0.73(0.66-1.00)$ & $0.76(0.69-1.00)$ & $0.85(0.73-1.00)$ \\
\hline$\leq 0.66$ & $130(28.6)$ & $52(24.1)$ & 2804 (15.6) \\
\hline $0.67-0.73$ & 107 (23.6) & $54(25.0)$ & 3062 (17.0) \\
\hline $0.74-0.99$ & $103(22.7)$ & $49(22.7)$ & 4901 (27.2) \\
\hline 1.00 & $114(25.1)$ & $61(28.2)$ & 7230 (40.1) \\
\hline \multicolumn{4}{|l|}{ EQ-VAS } \\
\hline Median (Q1, Q3) & $70(50-80)$ & 75 (60-82) & $75(60-87)$ \\
\hline $0-50$ & $126(27.8)$ & $49(22.7)$ & 3279 (18.2) \\
\hline $51-70$ & $129(28.4)$ & $56(25.9)$ & 4067 (22.6) \\
\hline $71-80$ & $104(22.9)$ & $56(25.9)$ & $4812(26.7)$ \\
\hline $81-100$ & $95(20.9)$ & $55(25.5)$ & $5836(32.4)$ \\
\hline
\end{tabular}

to 6.34 ; table 5 ). In the multivariable model no covariate other than EQ-VAS was significantly associated with delay time.

There was no significant interaction between gender and EQ-VAS $(\mathrm{p}=0.290)$.

The subgroup analysis showed a tendency to a stronger relationship between EQ-VAS and delay time the closer in time the HRQL measurement was to the new AMI. In the patients who indicated EQ-VAS $\leq 50$ and suffered a new AMI within 325 days of the EQ-5D measurement, the adjusted OR was 4.40 (95\% CI 1.40 to 13.9) for a delay time of $\geq 2 \mathrm{~h}$. Conversely, in patients with a new AMI more than 325 days after the EQ-5D measurement, the corresponding adjusted OR was 2.52 (95\% CI 1.08 to 5.89$)$.

In contrast to EQ-VAS, the EQ-index had no significant influence on delay time, unadjusted OR 1.52, 95\% CI 0.85 to 2.73 and adjusted $1.42,95 \%$ CI 0.71 to 2.87 for the lowest compared to the highest quartile. The EQ-5D dimension anxiety/depression, chest pain and dyspnoea did not affect the time from symptom onset to hospital arrival (data not shown).

\section{Readmission}

Of the patients in the readmission population, $40 \%$ were readmitted to hospital at least once within the first year. The readmission frequency increased with each quartile of EQ-VAS and EQ-index, respectively (tables 3 and 4).
There was a higher risk of readmissions in patients reporting EQ-VAS $\leq 50$ compared to those reporting EQ-VAS 81-100 in the univariate analysis (OR 3.08, 95\% CI 1.71 to 5.53). However, in the multivariable model the OR decreased to 1.99 (95\% CI 0.90 to 4.38$)$ and was no longer significant (table 6).

Patients with an EQ-index of $\leq 0.73$ had higher risk of readmission than those scoring 1.0 in the unadjusted model (OR 2.27, 95\% CI 1.27 to 4.06). However, after adjustment the correlation did not remain significant (OR $1.59,95 \%$ CI 0.74 to 3.42 ).

Anxiety/depression, chest pain or dyspnoea had no significant influence on readmissions (data not shown).

\section{DISCUSSION}

This is the first study showing an independent association between one aspect of total health status (EQ-VAS) and delay time. Patients who indicated EQ-VAS $\leq 50$ had triple the risk for a delay time of $2 \mathrm{~h}$ or more after adjustment for important covariates. Patients who scored EQ-VAS $\leq 50$ had an increased risk of readmission during the first year after the AMI in the univariate analysis. However, the correlation did not remain significant after adjustment.

The study populations had age and gender distributions comparable to the total SEPHIA population, and to those in other studies measuring HRQL after AMI. ${ }^{24}$ Patients in the study were sicker than the total SEPHIA

\begin{tabular}{llll} 
Table 3 & EQ-VAS in relation to delay time and readmission \\
\hline & $\begin{array}{l}\text { Delay time (min) } \\
\text { Median (Q1-Q3) }\end{array}$ & $\begin{array}{l}\text { Delay time } \\
\mathbf{2} \mathbf{~ h}(\%)\end{array}$ & $\begin{array}{l}\text { Readmission } \\
\mathbf{( \% )}\end{array}$ \\
EQ-VAS & $\mathbf{N = 3 6 9}$ & $\mathbf{N}=\mathbf{3 6 9}$ & $\mathbf{N = 2 1 0}$ \\
\hline $0-50$ & $195(90-460)$ & 69 & 57 \\
$51-70$ & $160(95-495)$ & 61 & 46 \\
$71-80$ & $150(90-340)$ & 61 & 39 \\
$80-100$ & $114(80-315)$ & 49 & 30 \\
\hline
\end{tabular}

\begin{tabular}{llll} 
Table 4 & EQ-index in relation to delay time and readmission \\
\hline & $\begin{array}{l}\text { Delay time (min) } \\
\text { Median (Q1-Q3) }\end{array}$ & $\begin{array}{l}\text { Delay time } \\
\mathbf{2} \mathbf{~ h ~ ( \% ) ~} \\
\mathbf{N}=\mathbf{4 2 5}\end{array}$ & $\begin{array}{l}\text { Readmission } \\
(\%)\end{array}$ \\
EQ-index & $\mathbf{N}=\mathbf{2 1 6}$ & 63 & 54 \\
\hline-0.66 & $180(90-445)$ & 63 & 54 \\
$0.67-0.73$ & $145(90-335)$ & 63 & 35 \\
$0.74-0.99$ & $151(80-345)$ & 57 & 30 \\
1.00 & $150(90-685)$ & 59 & \\
\hline
\end{tabular}


Table 5 Delay time

\begin{tabular}{|c|c|c|c|c|}
\hline Variables & Univariate OR (95\% CI) & p Value & $\begin{array}{l}\text { EQ-VAS } \\
\text { Multivariate OR }(95 \% \mathrm{Cl})\end{array}$ & p Value \\
\hline \multicolumn{5}{|l|}{ EQ-VAS } \\
\hline $0-50$ & $2.86(1.47$ to 5.54$)$ & 0.002 & $3.01(1.43$ to 6.34$)$ & 0.004 \\
\hline $51-70$ & $1.82(0.95$ to 3.48$)$ & 0.070 & $1.81(0.90$ to 3.66$)$ & 0.096 \\
\hline $71-80$ & 1.76 (1.02 to 3.05$)$ & 0.044 & 1.78 (1.04 to 3.05$)$ & 0.035 \\
\hline $81-100$ & Reference & & Reference & \\
\hline Age & $1.00(0.97$ to 1.03$)$ & 0.905 & $1.00(0.97$ to 1.03$)$ & 0.991 \\
\hline Ambulance to the cardiology department/PCI unit & $0.37(0.22$ to 0.63$)$ & $<0.001$ & $0.78(0.33$ to 1.81$)$ & 0.557 \\
\hline Ambulance to the emergency department & $0.44(0.26$ to 0.74$)$ & 0.002 & $0.54(0.26$ to 1.11$)$ & 0.094 \\
\hline Diabetes mellitus & $1.23(0.79$ to 1.84$)$ & 0.391 & $0.93(0.52$ to 1.66$)$ & 0.801 \\
\hline Women & 1.81 (1.04 to 3.17$)$ & 0.036 & $1.51(0.79$ to 2.87$)$ & 0.209 \\
\hline History of heart failure & $1.14(0.69$ to 1.91$)$ & 0.607 & $1.00(0.49$ to 2.03$)$ & 1.000 \\
\hline Hypertension & 1.33 (0.86 to 2.05$)$ & 0.198 & $1.21(0.74$ to 2.00$)$ & 0.446 \\
\hline Prehospital ECG & 0.49 (0.33 to 0.73$)$ & $<0.001$ & $0.67(0.40$ to 1.12$)$ & 0.124 \\
\hline Prior PCl & $0.78(0.49$ to 1.25$)$ & 0.306 & $0.99(0.56$ to 1.74$)$ & 0.964 \\
\hline Prior stroke & $0.87(0.47$ to 1.61$)$ & 0.661 & $0.68(0.31$ to 1.48$)$ & 0.327 \\
\hline Prior cardiac surgery & 0.85 (0.49 to 1.48$)$ & 0.561 & $0.86(0.48$ to 1.55$)$ & 0.621 \\
\hline Pulmonary rales & $0.96(0.52$ to 1.76$)$ & 0.886 & 1.27 (0.63 to 2.59$)$ & 0.505 \\
\hline Reperfusion treatment & 1.74 (1.11 to 2.72$)$ & 0.016 & 1.28 (0.61 to 2.72$)$ & 0.514 \\
\hline STEMI & 1.81 (1.21 to 2.70$)$ & 0.004 & 1.11 (0.58 to 2.12$)$ & 0.760 \\
\hline \multicolumn{5}{|l|}{ Year } \\
\hline 2006 & $1.12(0.42$ to 3.01$)$ & 0.817 & 1.17 (0.39 to 3.46$)$ & 0.779 \\
\hline 2007 & $0.73(0.44$ to 1.20$)$ & 0.217 & $0.67(0.41$ to 1.08$)$ & 0.100 \\
\hline 2008 & $1.07(0.61$ to 1.88$)$ & 0.805 & $0.98(0.55$ to 1.74$)$ & 0.946 \\
\hline 2009 & Reference year & & Reference year & \\
\hline
\end{tabular}

Patients with a new AMI after 1-year follow-up, $n=369$.

OR with $95 \% \mathrm{Cl}$ from GEE logistic regression of the probability of delay time $(\geq 2 \mathrm{~h}$ ).

$p$ Value $<0.05$ for statistical significance [in bold].

AMI, acute myocardial infarction; GEE, generalised estimating equations; PCI, percutaneous coronary intervention; STEMI, ST-elevation myocardial infarction.

population and, for example, had more heart failure, diabetes and more cardiac medications, which might be explained by the fact that the study populations consisted of patients with at least two AMIs.

The majority of the patients had a delay time $\geq 2 \mathrm{~h}$, which is in accordance with other studies, ${ }^{25}{ }^{26}$ although the study patients arrived slightly earlier to hospital after symptom onset compared to patients in the total SEPHIA population.

In the current study the EQ-5D was measured 1 year after the initial AMI and in median 325 days before the new AMI. Influencing events could occur between the initial 1-year follow-up and the new event, but we estimated that the measurement might be considered to represent the patient's HRQL at the time of the new AMI. The HRQL has been shown to improve during the first year after an AMI. ${ }^{27}{ }^{28}$ However, in the SEPHIA register there are only minor differences in HRQL between the first follow-up (6-10 weeks post-AMI) and the second follow-up at 1-year. ${ }^{29}$ In patients with stable coronary artery disease, the HRQL has been found to be stable during the following 2 years. ${ }^{30}$ Furthermore, the reported EQ-5D scores were comparable to what was seen in another study examining patients with AMI. ${ }^{22}$ The study populations reported slightly worse HRQL scores 1 year after the AMI, compared to the total
SEPHIA population. Previous investigations have shown that reinfarction, comorbidities and readmission because of cardiac events influence HRQL negatively. ${ }^{24} 2131$

The EQ-VAS and EQ-index are not completely comparable, since the EQ-index was developed to reflect health status based on general population preferences, and EQ-VAS evaluates the patient's personal health state. Accordingly, the correlation between EQ-VAS and EQ-index was low to moderate in previous research ${ }^{22}$ as in the present study.

Our study showed that low EQ-VAS is associated with an increased delay from onset of symptoms to hospital arrival. The association was independent of other factors known to increase the delay time. One reason for the longer delay time in patients with poor total health status might be depression, since depression usually contributes to a lower quality of life. ${ }^{32}$ The lack of correlation between the EQ-5D dimension anxiety/depression and delay time in the current study suggests that depression was not the major underlying cause behind the relationship between low EQ-VAS and delay time. However, due to the small number of patients scoring more severe anxiety/depression, the lack of association should be interpreted cautiously. Socioeconomic factors might also be of importance since they have been shown 
Table 6 Readmission

\begin{tabular}{|c|c|c|c|c|}
\hline Variables & Univariate OR (95\% Cl) & p Value & $\begin{array}{l}\text { EQ-VAS } \\
\text { Multivariate OR }(95 \% \mathrm{CI})\end{array}$ & p Value \\
\hline \multicolumn{5}{|l|}{ EQ-VAS } \\
\hline $0-50$ & 3.08 (1.71 to 5.53$)$ & $<0.001$ & 1.99 (0.90 to 4.38$)$ & 0.087 \\
\hline $51-70$ & 2.03 (0.95 to 4.34$)$ & 0.068 & 1.57 (0.68 to 3.62$)$ & 0.292 \\
\hline $71-80$ & 2.04 (1.32 to 3.15$)$ & 0.001 & 1.14 (0.59 to 2.19$)$ & 0.698 \\
\hline $81-100$ & Reference & & Reference & \\
\hline Age & 1.05 (1.0 to 1.09$)$ & 0.013 & $1.03(0.99$ to 1.07$)$ & 0.127 \\
\hline Ambulance to cardiology department/PCI unit & $0.42(0.16$ to 1.08$)$ & 0.073 & $0.46(0.16$ to 1.33$)$ & 0.150 \\
\hline Ambulance to the emergency department & 1.77 (1.18 to 2.66$)$ & 0.006 & 1.27 (0.69 to 2.33$)$ & 0.441 \\
\hline Diabetes mellitus & 0.99 (0.54 to 1.82$)$ & 0.985 & 1.05 (0.58 to 1.90$)$ & 0.868 \\
\hline Women & $1.92(1.03$ to 3.58$)$ & 0.041 & $1.41(0.75$ to 2.64$)$ & 0.289 \\
\hline History of heart failure & 1.55 (0.63 to 3.81$)$ & 0.343 & $1.15(0.41$ to 3.24$)$ & 0.788 \\
\hline Hypertension & $0.99(0.50$ to 1.97$)$ & 0.976 & $1.39(0.83$ to 2.33$)$ & 0.205 \\
\hline Number of medications $0-4$ & $1.44(0.82$ to 2.54$)$ & 0.201 & $1.25(0.67$ to 2.32$)$ & 0.478 \\
\hline $\mathrm{PCl}$ during hospitalisation at index event & $0.37(0.25$ to 0.54$)$ & $<0.001$ & $0.44(0.23$ to 0.86$)$ & 0.016 \\
\hline $\mathrm{PCl}$ & 0.48 (0.24 to 0.96$)$ & 0.038 & 1.12 (0.57 to 2.22$)$ & 0.735 \\
\hline Prior stroke & $2.08(0.78$ to 5.53$)$ & 0.144 & $1.01(0.39$ to 2.58$)$ & 0.986 \\
\hline Prior cardiac surgery & 0.57 (0.34 to 0.93$)$ & 0.026 & $0.67(0.41$ to 1.10$)$ & 0.113 \\
\hline STEMI & $1.52(0.72$ to 3.19$)$ & 0.268 & $0.93(0.41$ to 2.14$)$ & 0.869 \\
\hline \multicolumn{5}{|l|}{ Year } \\
\hline 2006 & 1.07 (0.19 to 6.13$)$ & 0.943 & $2.07(0.34$ to 12.8$)$ & 0.433 \\
\hline 2007 & 2.10 (1.03 to 4.31$)$ & 0.042 & 1.89 (0.96 to 3.74$)$ & 0.067 \\
\hline 2008 & $1.72(0.78$ to 3.78$)$ & 0.176 & 1.67 (0.67 to 4.15$)$ & 0.270 \\
\hline 2009 & Reference year & & Reference year & \\
\hline \multicolumn{5}{|c|}{$\begin{array}{l}\text { Patients with two } 1 \text {-year follow-up registrations, } n=210 \text {. } \\
\text { OR with } 95 \% \mathrm{Cl} \text { from GEE logistic regression of the probability of readmission. } \\
\text { Reference for number of medications was } \geq 5 \text {. } \\
p \text { Value }<0.05 \text { for statistical significance [in bold]. }\end{array}$} \\
\hline
\end{tabular}

to affect $\mathrm{HRQL}^{33}$ as well as delay time. ${ }^{9}$ Unfortunately, we were unable to adjust for socioeconomic factors in this study. Social support after AMI is also a factor influencing HRQL. High support is shown to increase HRQL in physical and in mental functioning, and also decreases depressive symptoms. ${ }^{34}$ Therefore it is important to include relatives in all patient information.

Depressed patients are known to have longer delay times when seeking medical care for AMI. ${ }^{35}$ One way to decrease anxiety, depression, ${ }^{36}$ and also improve HRQL, $^{37}$ is by having patients participate in cardiac rehabilitation programmes.

In contrast to EQ-VAS, the EQ-index had no independent association with delay time. Thus, the EQ-VAS probably reflects factors of importance for delay time other than those covered by the five dimensions included in the EQ-index.

The frequency of readmissions for any reason within the first year was higher in this study population, compared to previous reports. ${ }^{29} 38$ The difference probably reflects that the study population was somewhat sicker.

Poor total health status, measured by EQ-VAS, was associated with a higher risk of readmission during the first year after an AMI in the univariate analysis. However, after adjustment for important covariates, the association was no longer statistically significant. In another study investigating patients with chronic heart failure, poor HRQL was shown to increase the risk of readmission to hospital. ${ }^{16}$ However, the ability to show an independent correlation was limited in the current study, with only 216 patients included in the analysis.

\section{Limitations}

This study has some further limitations beyond those already discussed above. It might not be possible to generalise the findings in the study to patients without a previous AMI or to those older than 75 years.

To determine the exact time of symptom onset is difficult, even though the patients are requested to state the time of symptom onset as precisely as possible. Also, in a small proportion of the study populations $(6.4 \%)$, data on time of symptom onset were missing. However, uncertainties about the symptom onset would probably lead to an underestimation of the association between HRQL and delay, rather than the opposite.

Another limitation was that much can happen to the patients between the first 1-year follow-up and the new MI, which might influence the HRQL.

Patients reporting poor total health status should be regarded as being at increased risk for delaying seeking medical care in the case of a new AMI, and probably also for readmissions. Patients with poor total health 
status should be identified at follow-up visits and preferably given more support and information. Prospective studies are warranted to evaluate whether psychological support or other methods aiming to improve HRQL also shorten delay times and decrease readmission rates.

\section{CONCLUSION}

Patients with post-AMI who reported poor total health status had an increased risk for long delay time from symptom onset to hospital arrival. However, the risk of readmission was not clearly influenced by the patients total health status.

Acknowledgements The authors would like to thank the Swedish Heart and Lung Association, Uppsala County Association against Heart and Lung Diseases and Uppsala University for their grants.

Funding Swedish Heart and Lung Association, Uppsala County Association against Heart and Lung Diseases and Uppsala University.

\section{Competing interests None.}

Ethics approval Regional Medical Ethical Committee in Uppsala, Sweden.

Provenance and peer review Not commissioned; externally peer reviewed.

Data sharing statement No additional data are available.

Open Access This is an Open Access article distributed in accordance with the Creative Commons Attribution Non Commercial (CC BY-NC 3.0) license, which permits others to distribute, remix, adapt, build upon this work noncommercially, and license their derivative works on different terms, provided the original work is properly cited and the use is non-commercial. See: http:// creativecommons.org/licenses/by-nc/3.0/

\section{REFERENCES}

1. Antman EM, Anbe DT, Armstrong PW, et al. ACC/AHA guidelines for the management of patients with ST-elevation myocardial infarction; a report of the American College of Cardiology/American Heart Association Task Force on Practice Guidelines (Committee to Revise the 1999 Guidelines for the Management of patients with acute myocardial infarction). J Am Coll Cardiol 2004;44:E1-211.

2. Boersma E, Maas AC, Deckers JW, et al. Early thrombolytic treatment in acute myocardial infarction: reappraisal of the golden hour. Lancet 1996;348:771-5.

3. Newby LK, Rutsch WR, Califf RM, et al. Time from symptom onset to treatment and outcomes after thrombolytic therapy. GUSTO-1 Investigators. J Am Coll Cardiol 1996;27:1646-55.

4. De Luca G, Suryapranata H, Ottervanger JP, et al. Time delay to treatment and mortality in primary angioplasty for acute myocardial infarction: every minute of delay counts. Circulation 2004;109:1223-5.

5. Juliard JM, Feldman LJ, Golmard JL, et al. Relation of mortality of primary angioplasty during acute myocardial infarction to door-to-Thrombolysis In Myocardial Infarction (TIMI) time. Am J Cardiol 2003;91:1401-5.

6. Goldberg RJ, Spencer FA, Fox KA, et al. Prehospital delay in patients with acute coronary syndromes (from the Global Registry of Acute Coronary Events [GRACE]). Am J Cardiol 2009;103:598-603.

7. McGinn AP, Rosamond WD, Goff DC, et al. Trends in prehospital delay time and use of emergency medical services for acute myocardial infarction: experience in 4 US communities from 1987-2000. Am Heart J 2005;150:392-400.

8. Ottesen MM, Dixen U, Torp-Pedersen C, et al. Prehospital delay in acute coronary syndrome-an analysis of the components of delay. Int J Cardiol 2004;96:97-103.

9. Nguyen HL, Saczynski JS, Gore JM, et al. Age and sex differences in duration of prehospital delay in patients with acute myocardial infarction: a systematic review. Circ Cardiovasc Qual Outcomes 2010;3:82-92.

10. Bunde J, Martin R. Depression and prehospital delay in the context of myocardial infarction. Psychosom Med 2006;68:51-7.

11. Milonas $\mathrm{C}$, Jernberg $\mathrm{T}$, Lindback J, et al. Effect of Angiotensin-converting enzyme inhibition on one-year mortality and frequency of repeat acute myocardial infarction in patients with acute myocardial infarction. Am J Cardiol 2010;105:1229-34.

12. Stenestrand $U$, Wallentin $L$. Early statin treatment following acute myocardial infarction and 1-year survival. JAMA 2001;285:430-6.

13. Squizzato A, Keller T, Romualdi E, et al. Clopidogrel plus aspirin versus aspirin alone for preventing cardiovascular disease. Cochrane Database Syst Rev 2011;(1):CD005158.

14. Janzon M, Levin LA, Swahn E. Invasive treatment in unstable coronary artery disease promotes health-related quality of life: results from the FRISC II trial. Am Heart J 2004;148:114-21.

15. Kurdyak PA, Gnam WH, Goering P, et al. The relationship between depressive symptoms, health service consumption, and prognosis after acute myocardial infarction: a prospective cohort study. BMC Health Serv Res 2008;8:200.

16. Iqbal J, Francis L, Reid J, et al. Quality of life in patients with chronic heart failure and their carers: a 3-year follow-up study assessing hospitalization and mortality. Eur J Heart Fail 2010;12:1002-8.

17. Swedeheart register, RIKS-HIA. 2009. http://www.ucr.uu.se/ swedeheart

18. Swedeheart register, SEPHIA. 2009. http://www.ucr.uu.se/ swedeheart

19. Brown N, Melville M, Gray D, et al. Quality of life four years after acute myocardial infarction: short form 36 scores compared with a normal population. Heart 1999;81:352-8.

20. Rabin R, de Charro F. EQ-5D: a measure of health status from the EuroQol Group. Ann Med 2001;33:337-43.

21. Ellis JJ, Eagle KA, Kline-Rogers EM, et al. Validation of the EQ-5D in patients with a history of acute coronary syndrome. Curr Med Res Opin 2005;21:1209-16.

22. Schweikert B, Hahmann H, Leidl R. Validation of the EuroQo questionnaire in cardiac rehabilitation. Heart 2006;92:62-7.

23. Hardin JW, Hilbe JM. Generalized estimating equations. Boca Raton, FL: Chapman \& Hall/CRC, 2003.

24. Schweikert B, Hunger M, Meisinger C, et al. Quality of life several years after myocardial infarction: comparing the MONICA/KORA registry to the general population. Eur Heart $J$ 2009;30:436-43.

25. Floyd KC, Yarzebski J, Spencer FA, et al. A 30-year perspective (1975-2005) into the changing landscape of patients hospitalized with initial acute myocardial infarction: Worcester Heart Attack Study. Circ Cardiovasc Qual Outcomes 2009;2:88-95.

26. Boersma E. Does time matter? A pooled analysis of randomized clinical trials comparing primary percutaneous coronary intervention and in-hospital fibrinolysis in acute myocardial infarction patients. Eur Heart J 2006;27:779-88.

27. Simpson E, Pilote L. Quality of life after acute myocardial infarction: a systematic review. Can J Cardiol 2003;19:507-11.

28. Brink E, Grankvist G, Karlson BW, et al. Health-related quality of life in women and men one year after acute myocardial infarction. Qual Life Res 2005;14:749-57.

29. SEPHIA yearly report. 2009. http://www.ucr.uu.se/swedeheart

30. Kiessling A, Henriksson P. Time trends of chest pain symptoms and health related quality of life in coronary artery disease. Health Qual Life Outcomes 2007:5:13.

31. Dixon T, Lim LL, Oldridge NB. The MacNew heart disease health-related quality of life instrument: reference data for users. Qual Life Res 2002;11:173-83.

32. de Jonge P, Spijkerman TA, van den Brink RH, et al. Depression after myocardial infarction is a risk factor for declining health related quality of life and increased disability and cardiac complaints at 12 months. Heart 2006;92:32-9.

33. Burstrom K, Johannesson M, Diderichsen F. Swedish population health-related quality of life results using the EQ-5D. Qual Life Res 2001;10:621-35.

34. Leifheit-Limson EC, Reid KJ, KasI SV, et al. Changes in social support within the early recovery period and outcomes after acute myocardial infarction. J Psychosom Res 2012;73:35-41.

35. Wong CK, Tang EW, Herbison $\mathrm{P}$, et al. Pre-existent depression in the 2 weeks before an acute coronary syndrome can be associated with delayed presentation of the heart attack. QJM 2008;101:137-44.

36. Yu CM, Lau CP, Chau J, et al. A short course of cardiac rehabilitation program is highly cost effective in improving long-term quality of life in patients with recent myocardial infarction or percutaneous coronary intervention. Arch Phys Med Rehabil 2004:85:1915-22.

37. Leung YW, Grewal K, Gravely-Witte S, et al. Quality of life following participation in cardiac rehabilitation programs of longer or shorter than 6 months: does duration matter? Popul Health Manag 2011:14:181-8.

38. Maddox TM, Reid KJ, Rumsfeld JS, et al. One-year health status outcomes of unstable angina versus myocardial infarction: a prospective, observational cohort study of ACS survivors. BMC Cardiovasc Disord 2007;7:28. 